2020-10-01

\title{
Mathematical modelling of concrete carbonation with moving boundary
}

\section{Li, Long-yuan}

http://hdl.handle.net/10026.1/16166

10.1016/j.icheatmasstransfer.2020.104809

International Communication of Heat and Mass Transfer

Elsevier BV

All content in PEARL is protected by copyright law. Author manuscripts are made available in accordance with publisher policies. Please cite only the published version using the details provided on the item record or document. In the absence of an open licence (e.g. Creative Commons), permissions for further reuse of content should be sought from the publisher or author. 
4

5

\section{Mathematical modelling of concrete carbonation with moving boundary}

Dawang Li ${ }^{\text {a }}$, Long-yuan $\mathrm{Li}^{\mathrm{b}}$, Xianfeng Wang ${ }^{\mathrm{a}, *}$

${ }^{a}$ Guangdong Provincial Key Laboratory of Durability for Marine Civil Engineering, Shenzhen

${ }^{\mathrm{b}}$ School of Engineering, University of Plymouth, Plymouth PL4 8AA, UK

\section{ABSTRACT}

This paper presents the mathematical models describing the diffusion of carbon-dioxide in concrete with considering the effect of concrete carbonation. The effect of concrete carbonation on carbon-dioxide diffusion is modelled by using a sink term added in the diffusion equation. It is shown that, when the carbonation reaction is much faster than the diffusion process, the diffusion of carbon-dioxide in carbonated concrete can be treated as the diffusion problem with a moving boundary, representing the diffusion front or the carbonation depth. An analytical solution is also derived for the diffusion problem with moving boundary.

Keywords: Modelling; carbon-dioxide; diffusion; concrete carbonation; moving boundary. 


\footnotetext{
* Corresponding author.

E-mail address: xfw@szu.edu.cn (X.F. Wang)
}

\section{Introduction}

The corrosion of steel in reinforced concrete structures is the major concern of infrastructure owners and operators. Two major causes that are connected to corrosion of reinforcing steel in concrete structures are the carbonation and chloride attack. Carbonation is a set of reactions between atmospheric carbon-dioxide and alkaline components of concrete, producing a carbonated surface layer in which the pore solution $\mathrm{pH}$ value is depressed to nearneutral levels $[1,2,3]$. A secondary effect of carbonation, also significant in terms of its influence on reinforcing steel corrosion, is that it can cause the release of bound chloride ions into the pore solution phase of concrete that contains a modest level of chloride salts as a contaminant, thus exacerbating the corrosive nature of the electrolyte $[4,5]$. The carbon-dioxide diffusion has been investigated in capillaries and in a cavity with $\mathrm{N}_{2}-\mathrm{CO}_{2}$ mixture [6,7]. A variable-density single-phase incompressible model has been developed for numerical simulation of the DDC (dissolution-diffusion-convection) process of carbon-dioxide [8]. In addition, carbonation can also influence the diffusion of chloride ions in concrete as it can alter the pore volume and pore structure and thus the transport properties of concrete $[9,10,11]$. In certain cases the permeability of carbonated concrete may increase, as in the case of concrete made with blended cements such as blast furnace slag and fly ash concrete $[9,10]$; in others, it may decrease as in ordinary Portland cement concrete $[4,11]$. In urban and industrial areas, 
where environmental pollution results in a significant concentration of carbon-dioxide, carbonation-initiated reinforcement corrosion prevails [12]. While in highways and marine or coastal structures, chloride ions, originating from deicing salts or seawater, are transported through the concrete pore network and micro-cracks and depassivate the oxide film covering the reinforcing steel and thus induce the corrosion of reinforcing steel [13]. The worst situation is when a concrete structure is subjected to both carbonation and chloride attack [14]. A recent study [15] reported that the probability of the corrosion initiation for the combined action of carbonation and chloride attack is almost two times higher than the case in which the two attacks are considered separately. This illustrates the difficulty that arises when the presence of more than one corrosion-inducing agent contributes to aggressiveness of the exposure conditions for a particular structure.

Extensive research work has been carried to understand how carbon-dioxide transports in concrete pore medium and how it reacts with cement products in concrete. Saetta et al. [16] presented a two-dimensional finite element model for the illustration of concrete carbonation mechanism. The model was used to analyse the effects of multi-dimensional moisture, heat and carbon-dioxide transport through concrete on the corrosion of a reinforcing bar placed at the corner of a concrete structure. Steffens et al. [17] developed a theoretical model to predict the carbonation of concrete structures. The model described the movement and retention of heat, moisture and carbon-dioxide by means of balance equations and diffusion laws. The governing equations of the model were solved numerically using finite element techniques. Liang and Lin [18] presented a mathematical model with a set of one-dimensional linear diffusion equations to simulate the transport problems of carbon-dioxide, chloride and sulphate ions in concrete. 
64

Isgor and Razaqpur [19] proposed a nonlinear finite element approach for modelling coupled heat transfer, moisture transport and carbonation processes in concrete for tracing the spatial and temporal advancement of the carbonation front in concrete structures with and without cracks. The numerical results were compared with available experimental data. Kumazaki [20] presented a mathematical model of carbon-dioxide transport in concrete carbonation process. The model was described by using a parabolic type equation with a nonlinear perturbation such that a coefficient of the time derivative contains a non-local term depending on the unknown function itself. Zhang [21] developed a mathematical model of carbonation process in porous concrete materials. The model was solved numerically using uncoupled finite volume method. Numerical simulations under normal and accelerated carbonation conditions were presented. Zhu et al. [22] proposed a comprehensive model to simulate the transports of carbon-dioxide, chloride ions, heat and moisture in concrete. The model was validated using several sets of experimental data.

The above survey of literature shows that many mathematical models have been developed to describe the carbonation phenomena in concrete. However, most of existing models are difficult to use either because they require too many input data or because they were developed for some specific application cases. In this paper a mathematical model describing the diffusion of carbon-dioxide in concrete with considering the effect of concrete carbonation is developed. The diffusion model is established using Fick's first law, whereas the effect of concrete carbonation on carbon-dioxide diffusion is modelled by using a sink term added in the diffusion equation. The present diffusion model is simplified to the diffusion problem with a moving boundary representing the diffusion front or the carbonation depth when the 
carbonation reaction is much faster than the diffusion process. An analytical solution is also derived from the diffusion problem of moving boundary for calculating corresponding carbonation depth.

\section{Modelling of carbon-dioxide diffusion in concrete with general carbonation reaction}

Concrete carbonation commonly takes place after the atmospheric carbon-dioxide, $\mathrm{CO}_{2}$, diffuses into concrete from the air through concrete gaseous phase. The chemical reactions occurring during concrete carbonation can be broken down into two stages. One is the dissolving of $\mathrm{CO}_{2}$ in pore solution and the other is the reaction of the dissolved $\mathrm{CO}_{2}$ with the hydration products (mainly calcium ions) within the cement phase of concrete. The detailed description of the reactions for concrete carbonation can be found in the work of Bary and Sellier [23]. Nevertheless, the following represents the main reaction taking place during the concrete carbonation [24],

$$
\mathrm{Ca}(\mathrm{OH})_{2}(\mathrm{~s} \rightarrow \mathrm{aq})+\mathrm{CO}_{2}(\mathrm{~g} \rightarrow \mathrm{aq}) \rightarrow \mathrm{CaCO}_{3}(\mathrm{aq} \rightarrow \mathrm{s})+\mathrm{H}_{2} \mathrm{O}(\mathrm{aq})
$$

where the dissolved $\mathrm{Ca}(\mathrm{OH})_{2}$ in pore solution will quickly decompose into calcium and hydroxide ions. Thus, Eq.(1) can be also expressed as follows,

$$
\mathrm{Ca}^{2+}(\mathrm{aq})+2 \mathrm{OH}^{-}(\mathrm{aq})+\mathrm{CO}_{2}(\mathrm{aq}) \rightarrow \mathrm{CaCO}_{3}(\mathrm{~s})+\mathrm{H}_{2} \mathrm{O}(\mathrm{aq})
$$

where "g", "aq" and "s" are the abbreviation of gaseous, aqueous and solid phase, respectively. The transport of $\mathrm{CO}_{2}$ in concrete gaseous phase can be described by using Fick laws with considering the consumption of $\mathrm{CO}_{2}$ due to carbonation as follows [25,26,27],

$$
\frac{\partial C}{\partial t}=\nabla(D \nabla C)-Q_{C O 2}
$$


where $C$ in $\mathrm{kg} / \mathrm{m}^{3}$ is the content of $\mathrm{CO}_{2}$ freely diffusing in concrete gaseous phase, $t$ in $\mathrm{s}$ is the time, $D$ in $\mathrm{m}^{2} / \mathrm{s}$ is the diffusion coefficient of $\mathrm{CO}_{2}$ in concrete gaseous phase, and $Q_{\mathrm{CO}}$ in $\mathrm{kg} /(\mathrm{s}-$ $\left.\mathrm{m}^{3}\right)$ is the sink term representing the consumption rate of $\mathrm{CO}_{2}$ due to carbonation, which can be approximated as follows $[21,28]$,

$$
Q_{C O 2}=\frac{\partial S}{\partial t}=k_{t}\left(S_{a}-S\right)
$$

where $S$ in $\mathrm{kg} / \mathrm{m}^{3}$ is the content of $\mathrm{CO}_{2}$ consumed due to carbonation, $k_{t}$ in $\mathrm{s}^{-1}$ is the reaction rate constant, and $S_{a}$ in $\mathrm{kg} / \mathrm{m}^{3}$ is the available content of $\mathrm{CO}_{2}$ that can be consumed at a given condition.

Assume that the calcium ions in the pore solution are initially uniformly distributed and the process of their transport in the pore solution is much slower than that of their reaction taking place during carbonation. In this case the carbonation rate will be mainly controlled by calcium ions and $S_{a}$ can be assumed to have the following expression,

$$
S_{a}=S_{\max }\left[1-\exp \left(-\frac{k_{a} C}{C_{s}}\right)\right]
$$

where $S_{\max }$ in $\mathrm{kg} / \mathrm{m}^{3}$ is the maximum content of $\mathrm{CO}_{2}$ that can be consumed in carbonation, $C_{s}$ in $\mathrm{kg} / \mathrm{m}^{3}$ is the content of $\mathrm{CO}_{2}$ on the exposed surface (i.e. the content of $\mathrm{CO}_{2}$ in environment where the concrete is exposed), and $k_{a}$ is a dimensionless constant, which is used to reflect the effect of $\mathrm{CO}_{2}$ concentration in gaseous phase on the relationship between $S_{a}$ and $S_{\max }$. The reaction rate constant $k_{t}$ and dimensionless constant $k_{a}$ can be determined using experimental data obtained from concrete carbonation tests. In general, they would be dependent on the temperature and relative humidity of the environment surrounding the concrete and the properties of concrete raw materials. Fig. 1 graphically shows the relationship between $S_{a}$ and $C$. It can be seen from the figure that when $k_{a} \rightarrow \infty, S_{a}=S_{\text {max }}$; indicating that $S_{a}$ is a constant 

except at the point of $C=0$. Substituting Eq.(5) into (3) and (4), it yields,

$$
\begin{aligned}
& \frac{\partial C}{\partial t}=\nabla(D \nabla C)-k_{t} S_{\max }\left[1-\exp \left(-\frac{k_{a} C}{C_{s}}\right)-\frac{S}{S_{\max }}\right] \\
& \frac{\partial S}{\partial t}=k_{t} S_{\max }\left[1-\exp \left(-\frac{k_{a} C}{C_{s}}\right)-\frac{S}{S_{\max }}\right]
\end{aligned}
$$

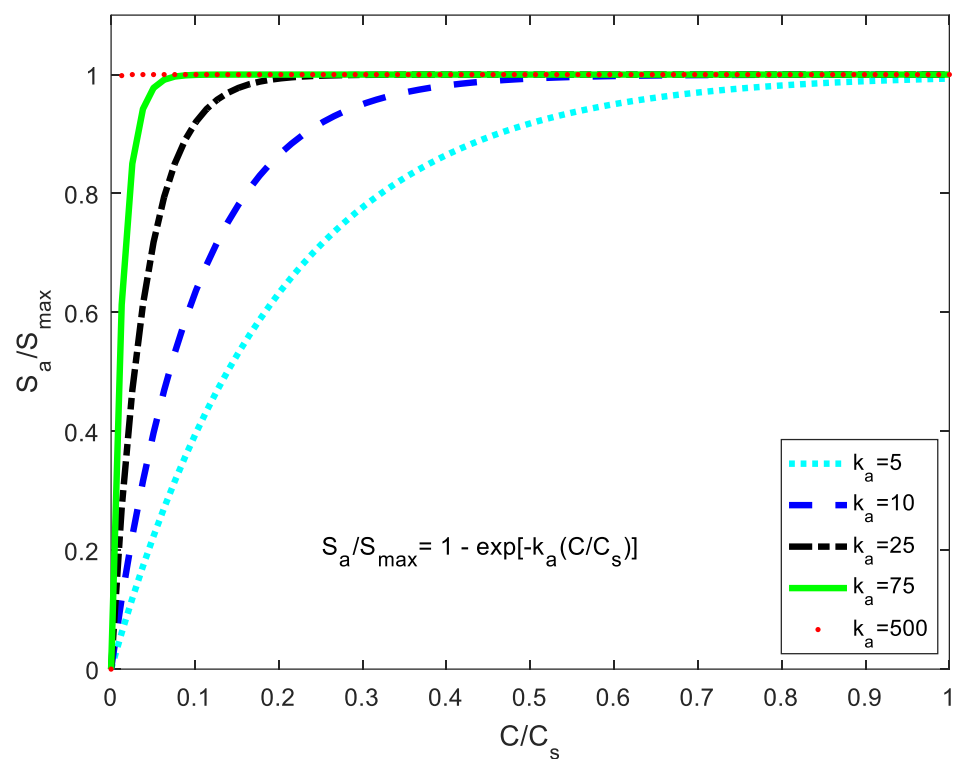

Fig. 1. Relationship between $S_{a}$ and $C$.

Eqs.(6) and (7) are the governing equations which can be used to determine the content of $\mathrm{CO}_{2}$ diffusing in concrete gaseous phase and the content of $\mathrm{CO}_{2}$ consumed during concrete carbonation. The corresponding initial and boundary conditions of $C(t, x)$ and $S(t, x)$ can be expressed as follows,

Initial conditions:

$$
C(0, x)=0
$$

$$
S(0, x)=0
$$

Boundary conditions:

$$
C(t, 0)=C_{s}, \quad C(t, \infty)=0
$$




$$
S(t, 0)=S_{\max }, \quad S(t, \infty)=0
$$

Eqs.(6)-(11) completely describe the transport problem of carbon-dioxide in concrete with taking into account the effect of concrete carbonation. Eqs.(6)-(11) can be solved using numerical methods such as the finite difference method [26,27]. Fig.2 shows the distribution 147 profiles of $C(t, x)$ and $S(t, x)$ at a given time for various different values of $k_{a}$ and $k_{t}$, obtained from the numerical solutions. It can be seen from the figure that the distribution pattern of the concentration profile of $\mathrm{CO}_{2}$ is more sensitive to the profile constant $k_{a}$ describing $S_{a}$ than to the reaction rate constant $k_{t}$. An important feature that can be observed is the idealized situation of $k_{a} \rightarrow \infty$ and $k_{t} / D \rightarrow \infty$ (red line shown in Fig.2) in which the diffusion of $\mathrm{CO}_{2}$ accompanied by the instantaneous and irreversible consumption of a limited amount of the diffusing $\mathrm{CO}_{2}$, leading to a sharp front of the consumed $\mathrm{CO}_{2}$. In front of the advancing boundary the content of the freely diffusing $\mathrm{CO}_{2}$ is zero, while behind it the content of the consumed $\mathrm{CO}_{2}$ is complete. fixed temperature, accompanied by the absorption or liberation of latent heat. 

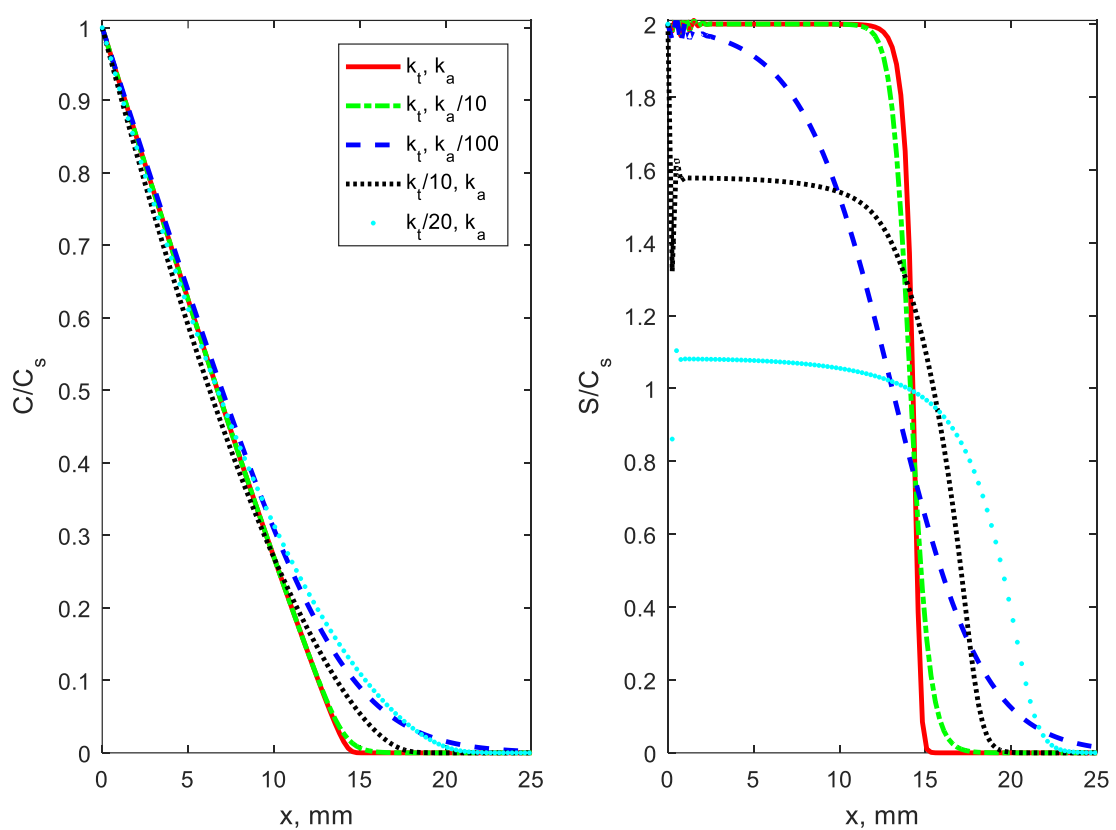

(a)

(b)

It is also observed from Fig.2 that when $k_{t}$ or $k_{a}$ is small the front of the consumed $\mathrm{CO}_{2}$ profile is not steeply straight but slowly decreases with increased distance, indicating that the carbonation reactions still take place in part of the carbonated zone. The transport of $\mathrm{CO}_{2}$ in the carbonated zone thus can be divided into two sub-zones. One is the fully carbonated zone in which the transport of $\mathrm{CO}_{2}$ is governed by diffusion only; the other is the partially carbonated zone in which the transport of $\mathrm{CO}_{2}$ is governed not only by diffusion but also by carbonation. As an example, Fig.3a shows the profiles of the consumed $\mathrm{CO}_{2}$ at various different times obtained from the present model. It is obvious from the figure that the carbonation reactions still take place in the zone behind the carbonation front. The carbonation depth for a given time 
can be obtained from the carbonation front. By identifying the carbonation fronts from the

174

175

profiles of consumed $\mathrm{CO}_{2}$ obtained at various different times we can find the relationship between the carbonation depth and exposure time, which is plotted in Fig.3b. To demonstrate the present model, experimental data [1] obtained from accelerated carbonation tests are also superimposed in the figure. The experimental work was carried out inside a test chamber with $\mathrm{CO}_{2}$ concentration about 50 percent. The specimens tested were mortars with high water-tocement ratio 0.8 . The parametric values used in the simulation are chosen to match the experimental data. The results shown herein illustrate that the relationship between the carbonation depth and exposure time may not necessarily follow the time square root relation when the carbonation reactions are not faster than the diffusion speed of $\mathrm{CO}_{2}$ in the gaseous phase. Note that, in many carbonation tests of concrete the carbonation depth is determined by using the phenolphthalein indicator solution $[25,28]$, which is a colourless acid/base indicator and can turn purple when its $\mathrm{pH}$ value exceeds 9. However, this test does not give the depth of maximum ingress of $\mathrm{CO}_{2}$ (i.e., the front point of partially carbonated zone) since the $\mathrm{CO}_{2}$ in the partially carbonated zone may cause a decrease in the $\mathrm{pH}$-value beyond the carbonation depth indicated by the phenolphtalein spray test, but their $\mathrm{pH}$ value may still be over 9 . 


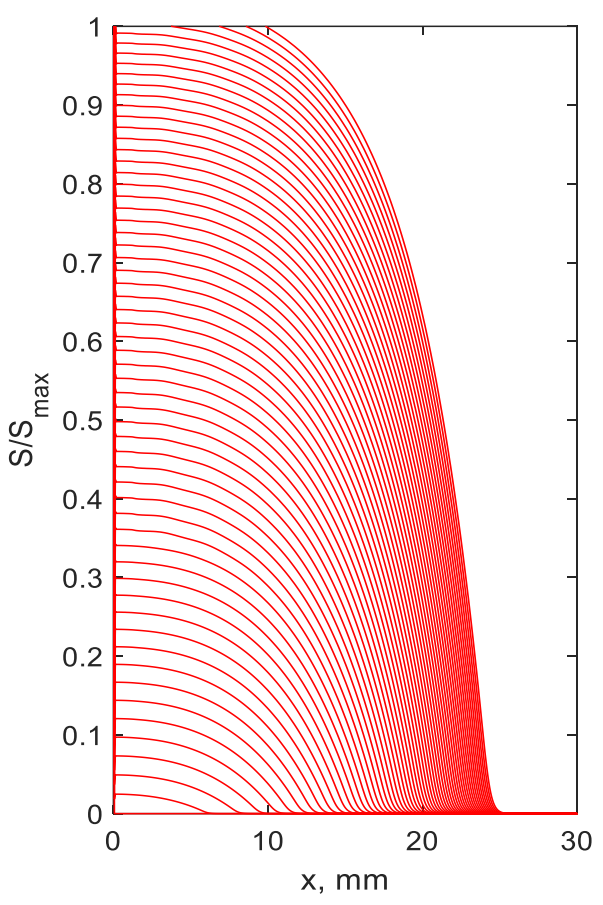

(a)

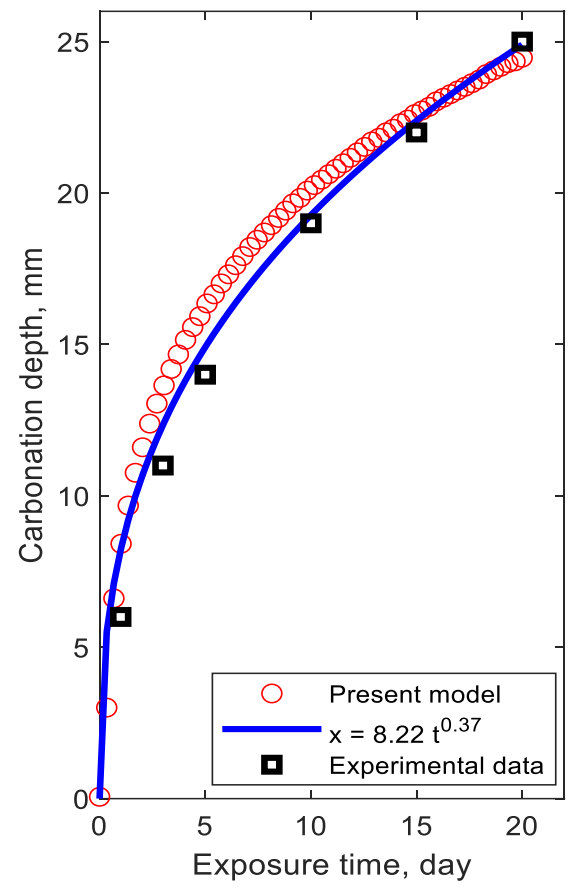

(b)
192

Fig. 3. (a) Profiles of consumed $\mathrm{CO}_{2}$ at various different times. (b) Variation of carbonation depth with exposure time $\left(k_{t}=4.25 \times 10^{-7} \mathrm{~s}^{-1}, k_{a}=5000, D=6.0 \times 10^{-11} \mathrm{~m}^{2} / \mathrm{s}\right)$.

In most cases, however, the chemical reaction between the carbonate ions and the calcium ions in pore solution is much quicker than the diffusion of the $\mathrm{CO}_{2}$ in the gaseous phase. Hence, the reaction can be assumed to take place only at the diffusion front, whereas the transport of $\mathrm{CO}_{2}$ can be assumed to take place only in the gaseous phase of the carbonated concrete. The consumption of $\mathrm{CO}_{2}$ in the diffusion front can be assumed to be controlled by the availability of the $\mathrm{Ca}(\mathrm{OH})_{2}$ or calcium ions in the pore solution. Under these assumptions, both $k_{a}$ and $k_{t} / D$ can be assumed to be infinitely large and the corresponding diffusion model described above requires only three constants $D, C_{s}$ and $S_{\max }$; each has a clearly physical meaning. Physically, this may represent the natural carbonation case where $\mathrm{CO}_{2}$ ingress is relatively slow, whereas 
the carbonation reaction is relatively fast.

205

Note that there is some numerical difficulty for solving Eqs.(6)-(11) when $k_{a} \rightarrow \infty$ and $k_{t} / D \rightarrow \infty$. Nevertheless, numerically, one can employ any large numbers for $k_{a}$ and $k_{t} / D$ to achieve the approximate solutions of the idealised case of $k_{a} \rightarrow \infty$ and $k_{t} / D \rightarrow \infty$. As a numerical example, Fig. 4 shows the distribution profiles of $C(t, x)$ and $S(t, x)$ obtained at three different times that correspond to the parametric values $\sqrt{D t}=8.82 \mathrm{~mm}, 12.5 \mathrm{~mm}$ and $15.3 \mathrm{~mm}$, respectively, when $k_{a}=500$ and $k_{t}=1.0 \times 10^{-6} \mathrm{~s}^{-1}\left(\sqrt{k_{t} / D}=211 \mathrm{~m}^{-1}\right)$ are employed. It is clear from the figure that the distribution profiles of $S(t, x)$ terminate nearly abruptly in all of the three times. The infinite gradient at the diffusion front leads to some oscillations in the start point of the profiles. This implies that if care was not taken in the selection of spatial and time intervals, the numerical solution may become inaccurate.
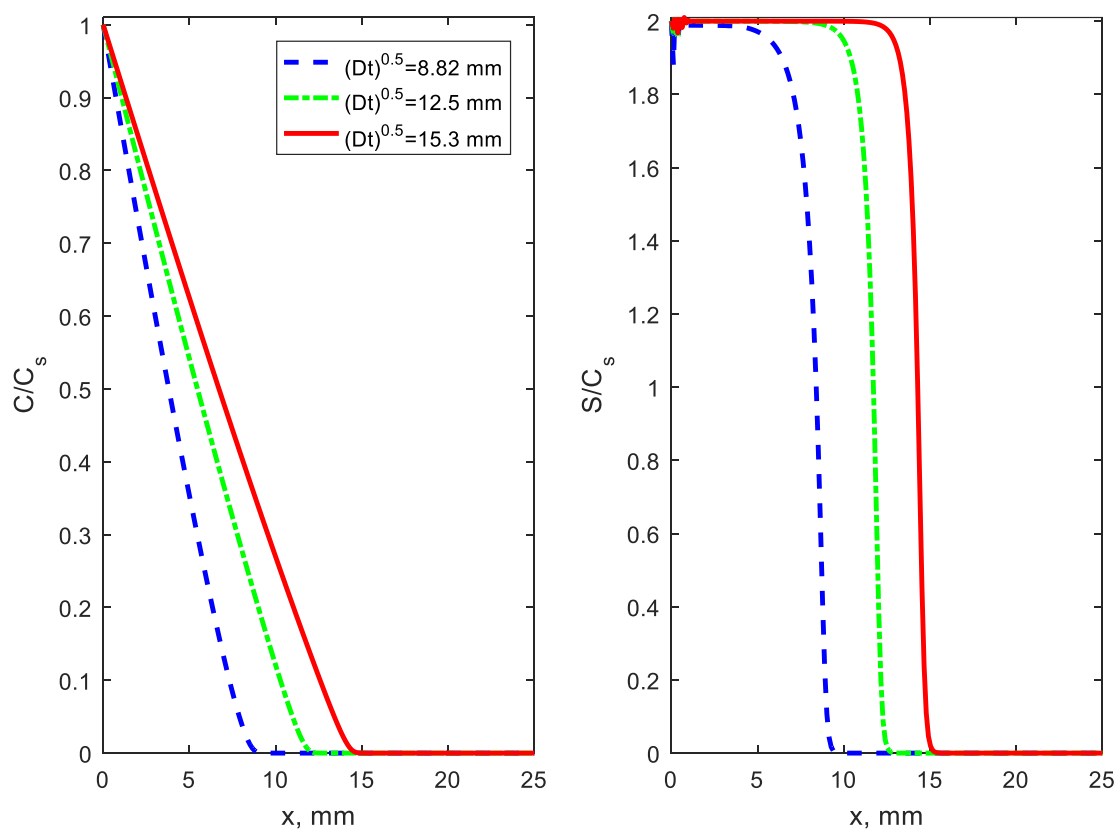

216

(a)

(b)

Fig. 4. Concentration profiles of (a) $\mathrm{CO}_{2}$ in gaseous phase and (b) consumed $\mathrm{CO}_{2}$ at different 


\section{Modelling of carbon-dioxide diffusion in concrete with fast carbonation reaction}

is slow the transport model described in Section 2 can be simplified by assuming $k_{a} \rightarrow \infty$ and

$k_{t} / D \rightarrow \infty$. To avoid the numerical difficulty when solving the idealised case of $k_{a} \rightarrow \infty$ and $k_{t} / D \rightarrow \infty$, the transport problem of carbon-dioxide in concrete with taking into account the effect of concrete carbonation described in Section 2 is now treated as the diffusion problem of particles in which part of particles are trapped in stationary holes. By considering the mass change of the total $\mathrm{CO}_{2}$ in a unit volume of concrete in a time interval $d t$, the following mass conservation equation can be established,

$$
\frac{\partial C_{T}}{\partial t}=\nabla(D \nabla C)
$$

where $C_{T}=C+S$ in $\mathrm{kg} / \mathrm{m}^{3}$ is the total content of $\mathrm{CO}_{2}$ in concrete. The right-hand-side of Eq.(12)

is the flux gradient based on the Fick's first law, in which $C$ in $\mathrm{kg} / \mathrm{m}^{3}$ is the content of $\mathrm{CO}_{2}$ freely diffusing in the gaseous phase of carbonated concrete. The initial and boundary conditions of $C_{T}(t, x)$ can be expressed as follows,

$$
\begin{aligned}
& C_{T}(0, x)=0 \\
& C_{T}(t, 0)=C_{s}+S_{\text {max }}, C_{T}(t, \infty)=0
\end{aligned}
$$

When solving Eqs.(12)-(14) for $C_{T}$ one has to know the content of $\mathrm{CO}_{2}$ in concrete gaseous phase, which is the function of $C_{T}$ and $S_{\max }$ and can be expressed as follows,

$$
C(t, x)=\left\{\begin{array}{cc}
C_{T}(t, x)-S_{\max } & C_{T}(t, x)>S_{\max } \\
0 & C_{T}(t, x) \leq S_{\max }
\end{array}\right.
$$


Note that, in the region of $C_{T}(t, x)>S_{\max }$ all holes are completely filled, whereas in the region of $C_{T}(t, x)<S_{\max }$ the holes are not completely filled and therefore $C(t, x)=0$. Eqs.(12)-(15) can be used for solving for $C_{T}(t, x)$ and thus $C(t, x)$ can be obtained. Compared to the model described in Section 2, the model presented herein by Eqs.(12)-(15) is much simple, clear, concise and easy to solve. As a numerical example, Fig.5 shows the distribution profiles of $C(t, x)$ and $S(t, x)$ at three different times obtained from the present model. For the purpose of comparison, the results obtained from the model described in Section 2 are also superimposed in the figure. It can be observed from the figure that there is almost no difference in the results of $C(t, x)$ obtained from the two models. There is only a small difference in the results of $S(t, x)$ at the diffusion front obtained from the two models. To examine the spatial-time relationship, Fig.6 replots the three profiles of $C_{T}(t, x)$ shown in Fig.5 but using a combined spatial and time coordinate, $x / \sqrt{ }(D t)$. It can be seen from the plot that when the combined coordinate is used the profiles at three different times are merged together, indicating that the diffusion depth of $\mathrm{CO}_{2}$ is proportional to the square root of the diffusing time. 
255

256

257

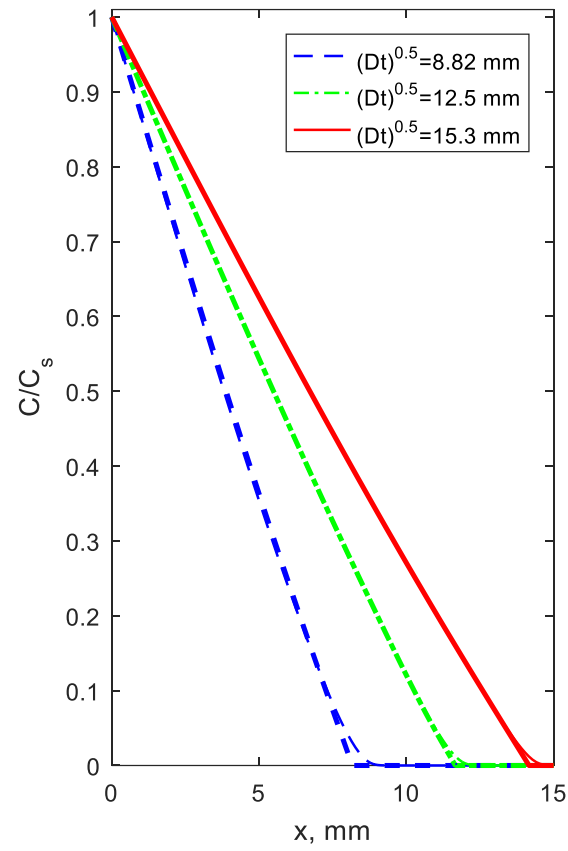

(a)

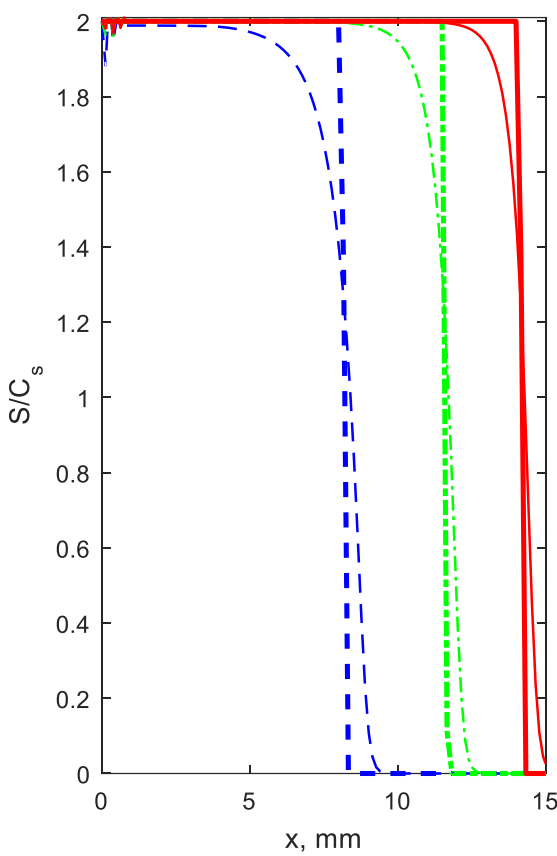

(b)

Fig. 5. Comparisons of (a) $\mathrm{CO}_{2}$ profiles and (b) consumed $\mathrm{CO}_{2}$ profiles between general and fast carbonation reaction models (thin and thick lines represent the results of general and fast reaction models, respectively, $\left.D=1.5 \times 10^{-11} \mathrm{~m}^{2} / \mathrm{s}\right)$.

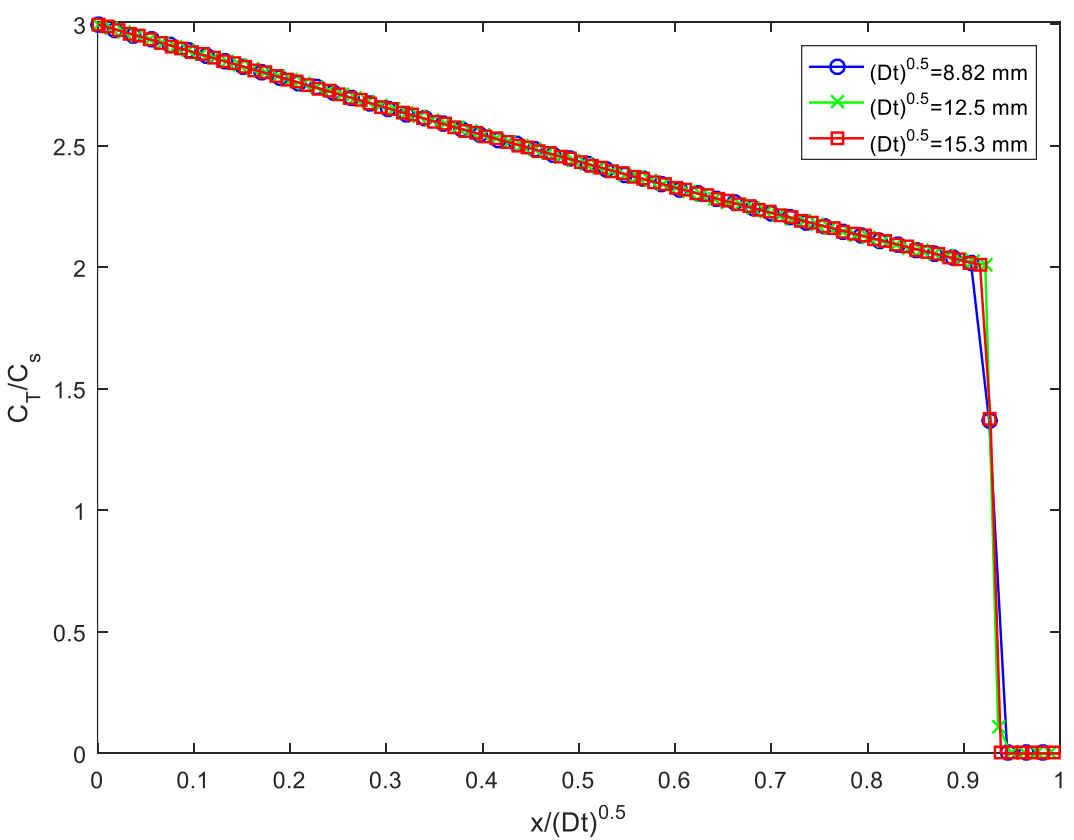

Fig. 6. Concentration profiles of total $\mathrm{CO}_{2}$ at three different times plotted against combined 


\section{Modelling of carbon-dioxide diffusion in concrete with moving boundary}

However, if it is applied only to the domain $(0<x<\xi)$ where $\xi$ is the diffusion front, then $\frac{\partial C_{T}}{\partial t}=$ $267 \frac{\partial C}{\partial t}$ since $S=S_{\max }$ is a constant in the domain $(0<x<\xi)$. Thus, Eq.(12) can be further simplified to Eq.(16),

Eqs.(16)-(18) represents the diffusion problem with moving boundary. As it is demonstrated in

Section 3, the depth of the diffusion front is proportional to square root of the diffusing time.

$$
\frac{\partial C}{\partial t}=\nabla(D \nabla C)
$$$$
0<x<\xi
$$

The initial and boundary conditions of $C(t, x)$ can be expressed as follows,

$$
\begin{aligned}
& C(0, x)=0 \\
& C(t, 0)=C_{s}, \quad C(t, \xi)=0
\end{aligned}
$$

Note that $\xi$ is the function of time, which moves forward when time increases. Thus Thus, the following expression can be assumed for $\xi(t)$,

$$
\xi(t)=k_{\xi} \sqrt{D t}
$$

where $k \xi$ is a constant to be determined. The solution of Eq.(16) with the initial and boundary conditions defined by Eqs.(17) and (18) can be expressed as follows,

$$
C(t, x)=C_{s}\left(1-\frac{\operatorname{erf}\left(\frac{x}{2 \sqrt{D t}}\right)}{\operatorname{erf}\left(\frac{k_{\xi}}{2}\right)}\right) \quad 0 \leq x \leq \xi
$$

where $\operatorname{erf}(\cdot)$ is the error function. It is obvious from Eq.(20) that if $k \xi$ is known then the solution 
equation need to be established at the point of the diffusion front, which can be expressed as

284 follows,

$$
-D \frac{\partial C}{\partial x}=S_{\max } \frac{d \xi}{d t} \quad \text { for } x=\xi
$$

Physically, the left-hand-side of Eq.(21) represents the diffusion flux from the diffusion zone into the zone ahead of the diffusion front; whereas the right-hand-side of Eq.(21) represents the flux required in order that the diffusion front can advance by a distance of $d \xi$ in the time interval of $d t$. Substituting Eqs.(19) and (20) into (21), it yields,

$$
\frac{k_{\xi}}{2} \operatorname{erf}\left(\frac{k_{\xi}}{2}\right) \exp \left(\frac{k_{\xi}^{2}}{4}\right)=\frac{C_{s}}{\sqrt{\pi} S_{\max }}
$$

Eq.(22) is a nonlinear algebraic equation about $k \xi$, which can be used to determine $k_{\xi}$ for a given ratio of $C_{s} / S_{\max }$. After $k \xi$ is determined it can be substituted into Eq.(19) for calculating the depth of diffusion front $\xi(t)$ and Eq.(20) for calculating the profile $C(t, x)$ of $\mathrm{CO}_{2}$. Fig.7 graphically shows the relationship between $k \xi$ and $C_{s} / S_{\max }$. It can be seen from the figure that $k \xi$ increases with $C_{s} / S_{\max }$; initially very quick but it becomes slow afterwards. It is clear from Eq. (19) that the influence of $C_{s} / S_{\max }$ on $\xi(t)$ is the same as that it does on $k \xi$. To demonstrate the analytical solutions presented by Eqs.(19) and (20), Fig.8 provides a comparison between the analytical solution given by Eqs.(19)-(20) and the numerical solutions given by Eqs.(12)(15) for the concentration distribution profile of freely diffusing $\mathrm{CO}_{2}$. As it is to be expected, there is no difference between the analytical and numerical solutions.

Of a particular interest is the case where $C_{s} / S_{\max }<<1$ and/or $k \xi<<1$, for which case the following approximation can be taken mathematically,

$$
\frac{k_{\xi}}{2} \operatorname{erf}\left(\frac{k_{\xi}}{2}\right) \exp \left(\frac{k_{\xi}^{2}}{4}\right) \approx \frac{k_{\xi}^{2}}{2 \sqrt{\pi}}
$$

Hence, Eq.(22) can be simplified as follows, 


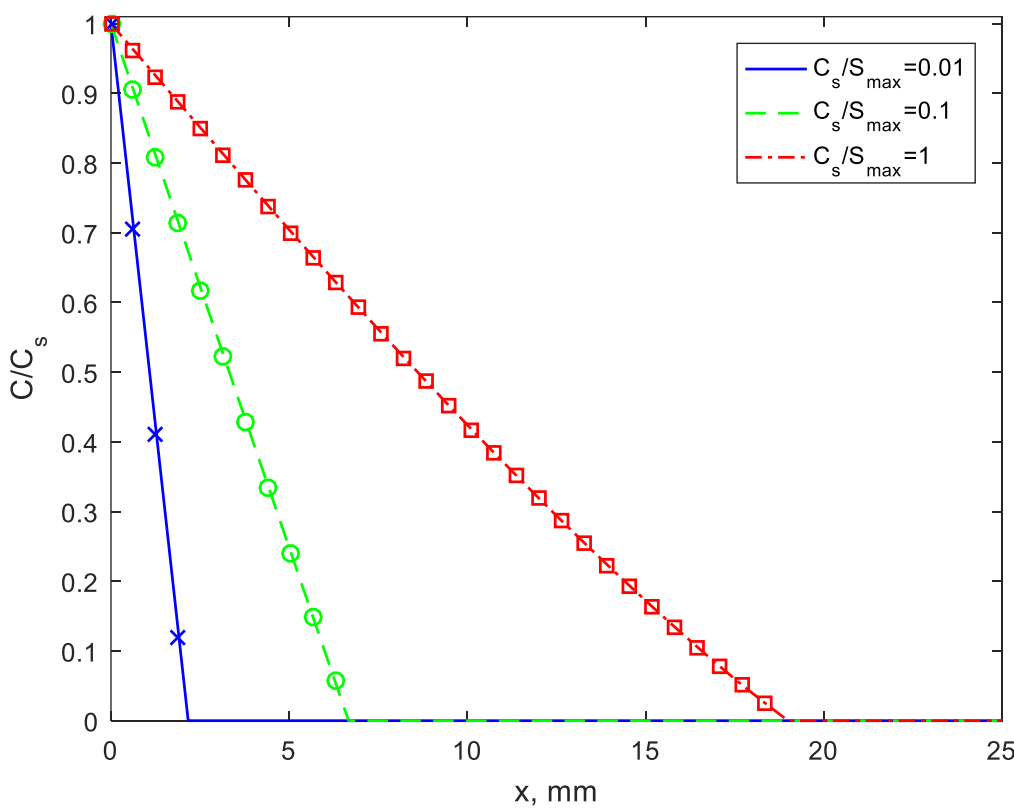

Fig. 7. Variation of $k \xi$ with $C_{s} / S_{\max }$.

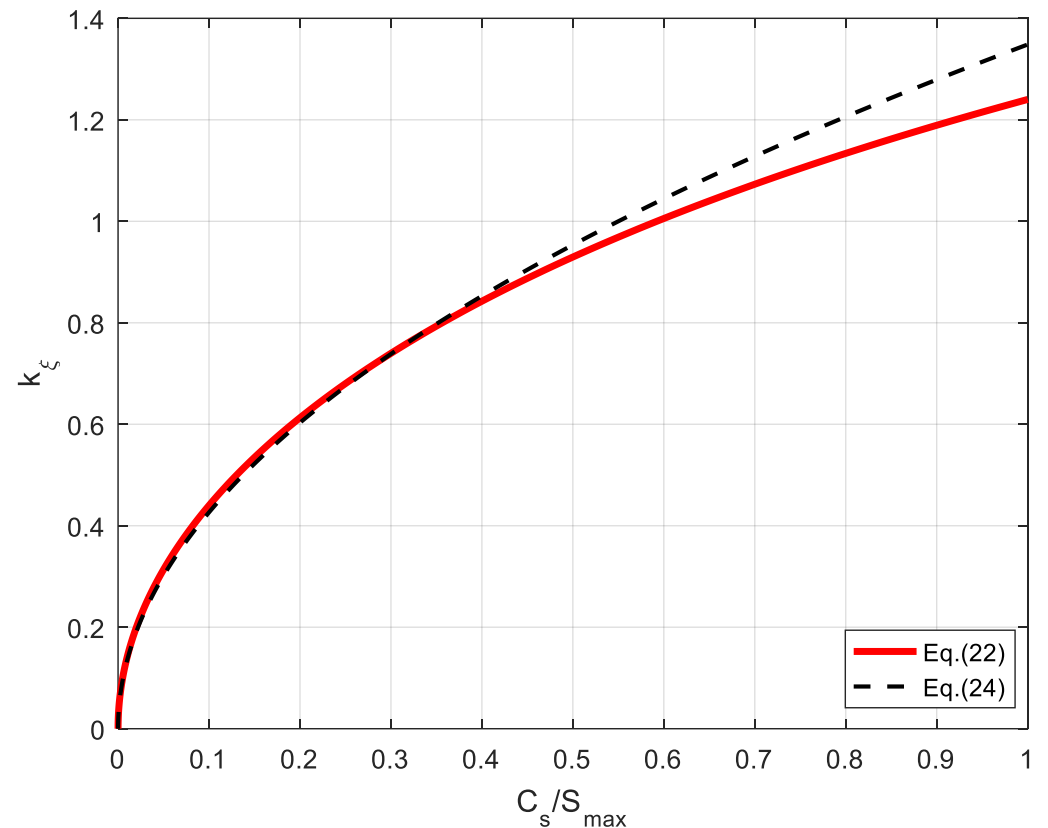

Fig. 8. Effect of $C_{s} / S_{\max }$ on $\mathrm{CO}_{2}$ profiles at time $\sqrt{ }(D t)=15.3 \mathrm{~mm}$ (lines are analytical solution given by Eqs.(19)-(20) and symbol points are numerical solutions given by Eqs.(12)-(15)).

$$
k_{\xi}=\sqrt{\frac{2 C_{s}}{S_{\max }}}
$$

The corresponding diffusion front $\xi(t)$ can be simplified as follows, 
Hyvert et al. [30], and Klopfer [31]. Experimental validation of Eq.(25) has been reported in literature, for example, [1,29,30,31,32], and thus is not provided herein. However, it is obvious from the above derivation that Eq.(25) is only limited to the case where the surface content of

$\mathrm{CO}_{2}$ is much lower than the consumed content of $\mathrm{CO}_{2}$ in carbonation; otherwise one has to use more accurate equation, Eq.(22), instead of its simplified form, Eq.(24), to calculate the carbonation depth. Fig.7 shows the difference between $k \xi$ calculated from Eq.(22) and that calculated from Eq.(24), from which one can clearly see the difference between them can be ignored for $C_{s} / S_{\max }<0.5$. Compared with existing work, not only can the present analytical solution be used to predict the carbonation depth but also to estimate the profile of $\mathrm{CO}_{2}$ in the carbonated concrete. reported that the $\mathrm{CO}_{2}$ level increases in recent years and was at $391 \mathrm{ppm}$ in March of 2011, which is $0.0391 \%$ of the atmosphere. The air density can be approximately taken as 1.225 of cement used in concrete, $M_{\mathrm{CO}_{2}}=44 \mathrm{~g} / \mathrm{mol}$ and $M_{\mathrm{CaO}}=56 \mathrm{~g} / \mathrm{mol}$ are the molar weight of $\mathrm{CO}_{2}$ and $\mathrm{CaO}$, respectively. For normal Portland cement concrete Cem is about $350 \mathrm{~kg} / \mathrm{m}^{3}$. This gives $S_{\max }=132 \mathrm{~kg} / \mathrm{m}^{3}$ and thus $C_{S} / S_{\max }=0.36 \times 10^{-5}$, which indicates that Eq.(24) can be safely 
used for most natural carbonation cases unless for specific laboratory tests where the concentration of $\mathrm{CO}_{2}$ used is much higher and the tested concrete is with supplementary cementitious materials (SCMs) which may reduce the content of the cement used in concrete.

\section{Conclusions}

In this paper we have presented the mathematical models to describe the diffusion of carbon-dioxide in concrete with considering the effect of concrete carbonation. Three models have been discussed, namely the diffusion model with general carbonation reaction, the diffusion model with fast carbonation reaction, and the diffusion model with moving boundary. Numerical solutions have been provided for the first two models, whereas analytical solution has been derived for the third model. Comparisons between the three models have been also provided, which illustrates their advantages and disadvantages. From the present study the following conclusions can be drawn:

- In the diffusion model with general carbonation reaction the distribution pattern of the concentration profile of $\mathrm{CO}_{2}$ is more sensitive to the profile constant $k_{a}$ describing $S_{a}$ than to the reaction rate constant $k_{t}$.

- It is more convenient to use the total concentration of $\mathrm{CO}_{2}$ to model the diffusion of $\mathrm{CO}_{2}$ in concrete with fast carbonation reaction, which avoids the difficulty of moving boundary. The diffusion front obtained from the numerical model for the diffusion model with fast carbonation reaction represents the carbonation depth.

- The analytical solution presented for the diffusion model with moving boundary can be 
directly used to examine the effects of diffusion coefficient of $\mathrm{CO}_{2}$ in carbonated concrete, diffusing time, and the ratio of $C_{s}$-to- $S_{\max }$ on the depth of concrete carbonation.

357

- It is demonstrated from the present analytical solution that the square root dependence of carbonation depth on $C_{s} / S_{\max }$ provided in many existing studies is appropriate only for the case where $C_{s} / S_{\max }$ is very small; otherwise more accurate nonlinear equation, Eq.(22), instead of its simplified form, Eq.(24), should be used for calculating the carbonation depth.

\section{Acknowledgements}

The authors would like to acknowledge the financial support received from the National Natural Science Foundation of China (Grant No. 51520105012). Part of the present work was also supported by the European Commission Research Executive Agency via a Marie Skłodowska-Curie Research and Innovation Staff Exchange project (H2020-MSCA-RISE2017, TRAC-777823).

\section{References}

[1] V.G. Papadakis, C.G. Vayena, M.N. Fardis, Fundamental modelling and experimental investigation of concrete carbonation. ACI Materials Journal 88(4) (1991) 363-373.

[2] A.V. Saettaa, R.V. Vitaliani, Experimental investigation and numerical modeling of carbonation process in reinforced concrete structures, Part I: theoretical formulation. Cement and Concrete Research 34(4) (2004) 571-579. 
[3] A.W. Islam, T.A. Meckel, A.Y. Sun, P.G. Krishnamurthy, Numerical experiments of density driven $\mathrm{CO}_{2}$ saturated brine migration in heterogeneous two-dimensional geologic fabric materials. Int. Comm. Heat Mass Transfer 71 (2016) 148-156.

[4] V.T. Ngala, C.L. Page, Effects of carbonation on pore structure and diffusion properties of hydrated cement pastes. Cement and Concrete Research 27(7) (1997) 995-1007.

[5] J. Geng, D. Easterbrook, Q.F. Liu, L.Y. Li, Effect of carbonation on releaseof bound chlorides in chloride-contaminated concrete. Magazine of Concrete Research 68(7) (2016) 353-363.

[6] M.E. Aguilera, A.L. de Ramos, Effect of $\mathrm{CO}_{2}$ diffusion on wettability for hydrocarbonwater- $\mathrm{CO}_{2}$ systems in capillaries. Int. Comm. Heat Mass Transfer 31(8) (2004) 11151122.

[7] A. Ibrahim, D. Lemonnier, Numerical study of coupled double-diffusive natural convection and radiation in a square cavity filled with $\mathrm{A} \mathrm{N}_{2}-\mathrm{CO}_{2}$ mixture. Int. Comm. Heat Mass Transfer 36(3) (2009) 197-202.

[8] H.Z. Yuan, X.R. Zhang, Numerical simulation with adaptive finite element methods for $\mathrm{CO}_{2}$ storage in saline aquifers. Int. Comm. Heat Mass Transfer 45 (2013) 55-63.

[9] R.K. Dhir, M.R. Jones, M.J. McCarthy, PFA concrete: Chloride ingress and corrosion in carbonated cover. Proceedings of the Institution of Civil Engineers: Structures and Buildings 99(2) (1993) 167-172.

[10] C. Yuan, D. Niu, D. Luo, Effect of carbonation on chloride diffusion in fly ash concrete. Disaster Advances 5(4) (2012) 433-436.

[11] W.P.S. Dias, Reduction of concrete sorptivity with age through carbonation. Cement and 
[12] I.S. Yoon, O. Copuroglu, K.B. Park, Effect of global climate change on carbonation progress of concrete. Atmospheric Environment 41(34) (2007) 7274-7285.

[13] M.F. Montemor, A.M.P. Simoes, M.G.S. Ferreira, Chloride-induced corrosion on reinforcing steel: from the fundamentals to the monitoring techniques. Cement and Concrete Composites 25(4-5) (2003) 491-502.

[14] M. Jin, S. Gao, L. Jiang, H. Chu, M. Lu, F.F. Zhi, Degradation of concrete with addition of mineral admixture due to free chloride ion penetration under the effect of carbonation. Corrosion Science 138 (2018) 42-53.

[15] X.J. Zhu, G.S. Zi, W.W. Lee, S.Y. Kim, J.S. Kong, Probabilistic analysis of reinforcement corrosion due to the combined action of carbonation and chloride ingress in concrete. Construction and Building Materials 124 (2016) 667-680.

[16] A.V. Saetta, B.A. Schrefler, R.V. Vitaliani, 2-D model for carbonation and moisture/heat flow in porous materials. Cement and Concrete Research 25(8) (1995) 1703-1712.

[17] A. Steffens, D. Dinkler, H. Ahrens, Modeling carbonation for corrosion risk prediction of concrete structures. Cement and Concrete Research 32(6) (2002) 935-941.

[18] M.T. Liang, S.M. Lin, Modeling the transport of multiple corrosive chemicals in concrete structures: Synergetic effect study. Cement and Concrete Research 33(12) (2003) 1917 1924.

[19] O.B. Isgor, A.G. Razaqpur, Finite element modeling of coupled heat transfer, moisture transport and carbonation processes in concrete structures. Cement and Concrete Composites 26(1) (2004) 57-73. 
419

420

421

422

423

424

425

426

427

[20] K. Kumazaki, A mathematical model of carbon dioxide transport in concrete carbonation process. Discrete and Continuous Dynamical Systems (Series S) 7(1) (2014) 113-125.

[21] Q. Zhang, Mathematical modeling and numerical study of carbonation in porous concrete materials. Applied Mathematics and Computation 281 (2016) 16-27.

[22] X.J. Zhu, G.S. Zi, Z.F. Cao, X.D. Cheng, Combined effect of carbonation and chloride ingress in concrete. Construction and Building Materials 110 (2016) 369-380.

[23] B. Bary, A. Sellier, Coupled-carbon dioxide-calcium transfer model for carbonation of concrete. Cement and Concrte Research 34(10) (2004) 1859-1872.

[24] M.A. Peter, A. Muntean, S.A. Meier, M. Böhm, Competition of several carbonation reactions in concrete: A parametric study. Cement and Concrete Research 38(12) (2008) 1385-1393.

[25] M. Thiery, G. Villain, P. Dangla, G. Platret, Investigation of the carbonation front shape on cementitious materials: Effects of the chemical kinetics. Cement and Concrete Research 37(7) (2007) 1047-1058.

[26] M.B.A. Monsour, Travelling wave solutions of a nonlinear reaction-diffusion-chemotaxis model for bacterial pattern formation. Applied Mathematical Modelling 32(2) (2008) 240-247.

[27] G. Carey, N. Fowkes, A. Staelens, A. Pardhanani, A class of coupled nonlinear reaction diffusion models exhibiting fingering. J. Comput. Appl. Math. 166(1) (2004) 87-99.

[28] RILEM, CPC-18 measurement of hardened concrete carbonation depth. Materials and Structures 21(6) (1988) 453-455.

[29] Y.F. Houst, F.H. Wittmann, Depth profiles of carbonates formed during natural carbonation. 
442 [30] N. Hyvert, A. Sellier, F. Duprat, P. Rougeau, P. Francisco, Dependency of C-S-H 443 carbonation rate on $\mathrm{CO}_{2}$ pressure to explain transition from accelerated tests to natural $444 \quad$ carbonation. Cement and Concrete Research 40(11) (2010) 1582-1589.

445 [31] H. Klopfer, The carbonation of external concrete and the control of it. Bautenschutz Bausanier 1(3) (1978) 86-97.

447

[32] K. Sisomphon, L. Franke, Carbonation rates of concretes containing high volume of pozzolanic materials. Cement and Concrete Research 37(12) (2007) 1647-1653.

[33] C. Pade, M. Guimaraes, The $\mathrm{CO}_{2}$ uptake of concrete in a 100 year perspective. Cement and Concrete Research 37(9) (2007) 1348-1356. 